\title{
Efficacy of walking aids on self-paced outdoor walking in individuals with COPD: A randomized cross-over trial
}

Citation for published version (APA):

Vaes, A. W., Meijer, K., Delbressine, J. M., Wiechert, J., Willems, P., Wouters, E. F. M., Franssen, F. M. E., \& Spruit, M. A. (2015). Efficacy of walking aids on self-paced outdoor walking in individuals with COPD: A randomized cross-over trial. Respirology, 20(6), 932-939. https://doi.org/10.1111/resp.12570

Document status and date:

Published: 01/01/2015

DOI:

10.1111/resp. 12570

Document Version:

Publisher's PDF, also known as Version of record

Document license:

Taverne

Please check the document version of this publication:

- A submitted manuscript is the version of the article upon submission and before peer-review. There can be important differences between the submitted version and the official published version of record.

People interested in the research are advised to contact the author for the final version of the publication, or visit the DOI to the publisher's website.

- The final author version and the galley proof are versions of the publication after peer review.

- The final published version features the final layout of the paper including the volume, issue and page numbers.

Link to publication

\footnotetext{
General rights rights.

- You may freely distribute the URL identifying the publication in the public portal. please follow below link for the End User Agreement:

www.umlib.nl/taverne-license

Take down policy

If you believe that this document breaches copyright please contact us at:

repository@maastrichtuniversity.nl

providing details and we will investigate your claim.
}

Copyright and moral rights for the publications made accessible in the public portal are retained by the authors and/or other copyright owners and it is a condition of accessing publications that users recognise and abide by the legal requirements associated with these

- Users may download and print one copy of any publication from the public portal for the purpose of private study or research.

- You may not further distribute the material or use it for any profit-making activity or commercial gain

If the publication is distributed under the terms of Article $25 \mathrm{fa}$ of the Dutch Copyright Act, indicated by the "Taverne" license above, 


\title{
Efficacy of walking aids on self-paced outdoor walking in individuals with COPD: A randomized cross-over trial
}

\author{
ANouk W. VAES, ${ }^{1,2}$ KenNeth MEIJER ${ }^{3}$ JeAnNet M. DELBRESSINE, ${ }^{1}$ JOZÉ WIECHERT ${ }^{4}$ \\ PAUl WILlEMS, ${ }^{3}$ EMIEL F.M. WOUTERS, ${ }^{1,5}$ FrITS M.E. FRANSSEN ${ }^{1}$ AND MARTIJN A. SPRUIT ${ }^{1}$
}

\begin{abstract}
${ }^{1}$ Program Development Centre, ${ }^{2}$ Physiotherapy, ${ }^{4}$ Occupational Therapy, ClRO+, Horn, ${ }^{3}$ Department of Human Movement Science, School for Nutrition, Toxicology and Metabolism and ${ }^{5}$ Department of Respiratory Medicine, MUMC+, Maastricht, The Netherlands
\end{abstract}

\begin{abstract}
Background and objective: Walking aids, such as rollator or draisine, improve mobility and functional exercise performance in individuals with chronic obstructive pulmonary disease (COPD) during an indoor 6-min walk test. However, this test does not reflect everyday walking, which is the most frequently reported problematic activity of daily life in individuals with COPD. To date, efficacy of walking aids during selfpaced outdoor walking remains unknown. Therefore, we aimed to determine the efficacy of a rollator and draisine on self-paced outdoor walking in individuals with COPD.

Methods: Fifteen individuals with COPD (68\% men; age: $63 \pm 8$ years; forced expiratory volume in 1 s: $40 \pm$ $14 \%$ predicted) performed three self-paced outdoor walking tests on two consecutive days: test 1 unaided, and tests 2 and 3 with rollator or draisine in random order. Participants had to walk as long as possible at their own pace. The test ended when participants needed to stop, with a maximum duration of $30 \mathrm{~min}$. Results: The use of rollator resulted in the highest walk distance and time $(P<0.05$ vs unaided and draisine). Furthermore, individuals with COPD walked significantly further and longer during an unaided test compared with a draisine aided test $(P<0.05)$. Moreover, use of draisine resulted in a significantly higher walking speed, fewer strides, greater stride length, and higher step and stride variability $(P<0.05$ vs unaided and rollator).

Conclusion: To conclude, a rollator improves the selfpaced outdoor walk distance and time in individuals with moderate and advanced COPD and a poor functional exercise capacity, whereas the use of a draisine had a detrimental effect compared with unaided walking.
\end{abstract}

Clinical trial registration: NTR1542 on www.trialregister.nl.

Correspondence: Anouk W. Vaes, Program Development Centre, $\mathrm{ClRO}+$, Centre of Expertise for Chronic Organ Failure, Hornerheide 1, 6085 NM Horn, The Netherlands. Email: anoukvaes@ciro-horn.nl

Received 12 August 2014; invited to revise 16 October 2014 and 17 February 2015; revised 27 October 2014 and 18 February 2015; accepted 5 March 2015 (Associate Editor: Neil Eves).

Article first published online: 17 June 2015

\section{SUMMARY AT A GLANCE}

This is the first study investigating the efficacy of walking aids during self-paced outdoor walking in individuals with COPD, showing that rollatoraided walking resulted in the highest walk distance and time, and that individuals with COPD walked significantly further and longer during unaided walking compared with a draisine-aided walking.

Key words: chronic obstructive pulmonary disease, motor activity, exercise, walking, walker.

Abbreviations: 6MWD, 6-min walk distance; 6MWT, 6-min walk test; $A P$, anteroposterior axis; bpm, beats per minute; COPD, chronic obstructive pulmonary disease; $\mathrm{FEV}_{1}$, forced expiratory volume in $1 \mathrm{~s}$; FFM, fat free mass; FVC, forced vital capacity; HR, heart rate; $\mathrm{ML}$, mediolateral axis; $\mathrm{SpO}_{2}$, saturation of peripheral oxygen; SPOW, self-paced outdoor walk; $V$, vertical axis.

\section{INTRODUCTION}

Walking aids generally improve functional exercise performance in individuals with chronic obstructive pulmonary disease (COPD).$^{1-5}$ For example, the use of a rollator resulted in clinically relevant improvements in the indoor 6-min walk distance (6MWD), and reduced exercise-induced dyspnoea and improved walking economy. ${ }^{1,24-6}$ Moreover, the use of a draisine, a bicycle without pedals, improved the 6MWD even to a greater extent compared with a rollator-aided 6 -min walk test (6MWT), while metabolic requirements and exercise-related symptoms were comparable. ${ }^{4}$

It seems reasonable to hypothesize that self-paced outdoor walk (SPOW) distance, duration and speed will improve in individuals with COPD using a rollator or draisine. To date, however, the efficacy of walking aids on outdoor use remains unknown, as an indoor 6MWT does not reflect self-paced outdoor walking. ${ }^{7}$ Then again, individuals with COPD appear to be satisfied with the self-reported effectiveness of rollator use for outdoor ambulation. ${ }^{8}$ 
We sought to determine the efficacy of a rollator and draisine on SPOW distance, time and speed in individuals with COPD. Moreover, we aimed to assess walk pattern, exercise-induced symptoms and user satisfaction. A priori, we hypothesized that individuals with COPD have a higher SPOW distance, time and speed while using the rollator compared with unaided walking. Moreover, we hypothesized that individuals with COPD have more benefit from the use of a draisine compared with unaided or rollatoraided walking, since it is related to lower costs of transport and a more effective walking pattern. ${ }^{4}$

\section{METHODS}

\section{Design}

This trial followed a prospective randomized crossover design. Individuals with COPD with a $6 \mathrm{MWD} \leq$ $500 \mathrm{~m}$, without a COPD exacerbation in the past 4 weeks, and without known musculoskeletal, cardiovascular or neurological disorders and ability to walk unaided, were eligible to participate. Subjects gave written informed consent to participate in this trial, which was approved by the medical ethical committee of the Maastricht University Medical Centre (MEC 08-3-069). The project was registered on www.trialregister.nl (NTR1542) before enrolment of the first participant.

\section{Study protocol}

Individuals with COPD were recruited at CIRO+, centre of expertise for chronic organ failure in Horn (the Netherlands). ${ }^{9}$ During routine pre-rehabilitation assessment, pulmonary function, peak aerobic capacity and body composition were determined as described before. ${ }^{10}$ In addition, functional exercise performance was determined using the 6MWT, including a practice walk. ${ }^{11}$ Individuals with a $6 \mathrm{MWD} \leq 500 \mathrm{~m}$ were eligible to participate, as they were expected to benefit most from the use of walking aids. ${ }^{12}$

Eligible participants were asked to perform three SPOW on two consecutive weekdays. Participants started with an unaided SPOW on day one. In addition, participants were randomly assigned, to do a SPOW with rollator on day one, followed by a SPOW with the draisine on day two, or vice versa (Fig. 1). Participants had a minimum of $3 \mathrm{~h}$ rest between the unaided SPOW and the aided SPOW on day one.

Before the start of the SPOW, participants were familiarized with both walking aids through an outdoor practice session of $15 \mathrm{~min}$ in combination with verbal instruction. See Supplementary Appendix S1 for specifications and settings of both walking aids and instructions during practice session. Participants receiving long-term oxygen therapy used the basket of the rollator or the draisine to transport their oxygen cylinder or a portable system on their waist.

\section{Self-paced outdoor walk}

The efficacy of the walking aids was determined using a SPOW. The SPOW was designed to provide more patient-meaningful information on walking ability. ${ }^{13}$ Because it reports absolute time, the SPOW can be used to evaluate whether and to what extent individuals with COPD are able to walk longer, one of the most common goals described by individuals with COPD entering pulmonary rehabilitation. ${ }^{14}$

All SPOW was performed on the same 250-m trail, which was divided into four sections: (1) flat surface, $78 \mathrm{~m}$; (2) some curves and a small slope up and down, $76 \mathrm{~m}$; (3) flat surface (same as Section 1), $78 \mathrm{~m}$; and (4) flat surface with turning point, $18 \mathrm{~m}$. The investigators showed the outdoor walking route to all participants before performing the SPOW, by using a wheelchair if necessary. All participants received standardized instructions to walk for as long as possible at their own pace, with a maximum duration of $30 \mathrm{~min}$. Test ended when participants needed to stop due to intolerable dyspnoea and/or leg fatigue.

Weather conditions during SPOW were noted. No information about wind was available. However, since the test was performed in a sheltered area, surrounded by buildings and trees, the wind should not have had a major influence on the different SPOW.

\section{Patient's satisfaction}

After both aided SPOW, participants were asked to answer two questions about the use of the walking aid, and five questions about feelings of embarrassment while using the aid (see Supplementary Appen$\operatorname{dix} \mathrm{S} 1)^{4}$

In addition, eight participants also filled out a questionnaire to determine their satisfaction with the walking aids (Supplementary Appendix S1). These satisfaction items were derived from the Dutch version of the Quebec User Evaluation of Satisfaction with Assistive Technology 2.0 (D-QUEST), which is a generic standardized instrument designed to assess satisfaction with assistive technology. ${ }^{15,16}$ The QUEST has been shown to yield reliable and valid results, ${ }^{15,16}$ and has been used before in patients with COPD. ${ }^{8}$ The QUEST consists of 12 items related to device characteristics $(n=8)$ and assistive technology services $(n=4) .{ }^{15}$ The items are scored using a 5-point satisfaction scale ranging from 'not satisfied at all' to 'very satisfied', where higher scores indicate greater satisfaction. In this study, items on assistive technology services were not applicable, and in turn were not scored. Moreover, by using only items on device characteristics, a good indication about users' satisfaction about the walking aids was obtained.

\section{Outcomes}

Primary outcomes were difference in walk distance, time and speed between an unaided, rollator-aided and draisine-aided SPOW. In addition, several explanatory outcomes were assessed: amount of strides, stride length, stride frequency, walk ratio, and step and stride variability in mediolateral, vertical and anteroposterior direction using two triaxial accelerometers (KXP94, Kionix Inc, Ithaca, NY, USA); transcutaneous oxygen saturation, heart rate and Borg symptom scores for dyspnoea and fatigue ${ }^{17}$ before 


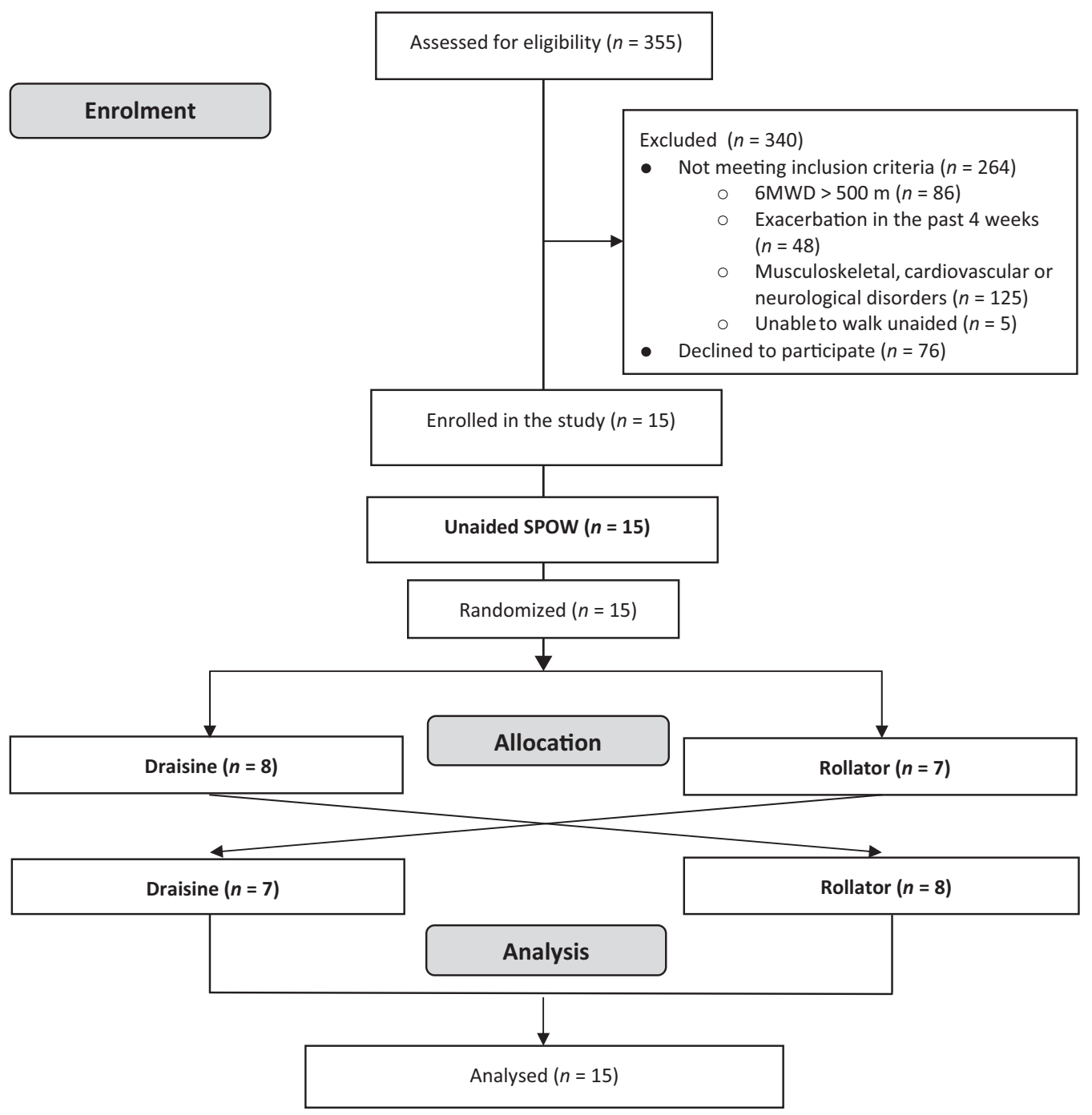

Figure 1 Disposition of participants. 6MWD, 6-min walk distance; SPOW, self-paced outdoor walk.

and after each SPOW; and preferences for the walking aids. Please see Supplementary Appendix S1 for additional information.

\section{Statistical analysis}

Data are presented as mean and standard deviation, unless noted otherwise. Analysis of variance with posthoc tests was used to assess differences between use of rollator and draisine. The level of significance was set at $\leq 0.05$. No adjustment was made to the statistical significance level for multiple comparisons. ${ }^{18}$ All data were analysed with SPSS 19.0 (IBM, Chicago, IL, USA).

A priori, we have calculated the minimum sample size to achieve adequate power. Based on Lacasse et al. ${ }^{19}$ we should include 16 participants to achieve a mean difference of $50 \mathrm{~m}$ (standard deviation $35 \mathrm{~m}$ ) (two-sided $P$-value: $<0.05$, probability: $90 \%$ ).

Matlab (Mathworks, Natick, MA, USA) was used to analyse the raw acceleration data of the accelerometers. Please see Supplementary Appendix S1 for additional information.

\section{RESULTS}

Two hundred sixty-four of the 335 subjects screened between March 2011 and December 2012 did not meet the inclusion criteria. In addition, 76 eligible subjects declined participation because of lack of interest. Characteristics of these participants were not significantly different from those enrolled in this trial. Finally, 15 individuals with COPD completed unaided, rollator-aided and draisine-aided SPOW (Fig. 1).

Weather conditions were similar during the different SPOW (see Supplementary Appendix S1 and Table S1).

\section{Patient characteristics}

On average, participants had moderate to very severe COPD, a normal body mass index and normal fat-free mass index (Table 1). The best 6MWD during prerehabilitation assessment was $404 \pm 6 \mathrm{~m}$. Two participants $(13 \%)$ used long-term oxygen therapy using a 
Table 1 Baseline characteristics $(n=15)$

\begin{tabular}{|c|c|}
\hline \multicolumn{2}{|l|}{ Demographics } \\
\hline Men (\%) & 66.7 \\
\hline Age (years) & $63.3(8.2)$ \\
\hline \multicolumn{2}{|l|}{ Pulmonary function } \\
\hline $\mathrm{FEV}_{1}(\mathrm{~L})$ & $1.1(0.4)$ \\
\hline $\mathrm{FEV}_{1}(\%$ predicted $)$ & $39.7(14.1)$ \\
\hline $\mathrm{FEV}_{1} / \mathrm{FVC}(\%)$ & $35.3(11.7)$ \\
\hline GOLD stage I/II/III/IV $(n)$ & $0 / 3 / 9 / 3$ \\
\hline MMRC grade $0 / 1 / 2 / 3 / 4(n)$ & $0 / 0 / 3 / 9 / 3$ \\
\hline \multicolumn{2}{|l|}{ Body composition } \\
\hline Body weight $(\mathrm{kg})^{\dagger}$ & 72.5 (22.8) \\
\hline Body mass index $\left(\mathrm{kg} / \mathrm{m}^{2}\right)$ & $25.1(6.9)$ \\
\hline FFM $(k g)$ & $49.5(12.6)$ \\
\hline FFMI $\left(\mathrm{kg} / \mathrm{m}^{2}\right)$ & $17.2(3.7)$ \\
\hline 6MWD (m) & $404(61.3)$ \\
\hline HR before (bpm) & $85.2(9.9)$ \\
\hline HR after (bpm) & $109.7(13.0)$ \\
\hline $\mathrm{SpO}_{2}$ before $(\%)$ & $94.8(2.7)$ \\
\hline $\mathrm{SpO}_{2}$ drop (\%) & $5.8(4.7)$ \\
\hline Borg dyspnoea (points) & $5.3(1.7)$ \\
\hline Borg fatigue (points) & $4.5(2.2)$ \\
\hline
\end{tabular}

Results are presented as mean (standard deviation).

${ }^{\dagger} 1 \mathrm{~kg}=2.2046 \mathrm{lbs}$.

6MWD, 6-min walk distance; $\mathrm{FEV}_{1}$, forced expiratory volume in $1 \mathrm{~s}$; FFM, fat free mass; FFMI, fat-free mass index; FVC, forced vital capacity; GOLD, Global Initiative for Chronic Obstructive Lung Disease; HR, heart rate; MMRC, Modified Medical Research Council.

portable system on their waist. None of the participants used a walking aid at the time of the study.

\section{Effects on SPOW distance, time and speed}

The use of a rollator resulted in a significantly higher mean SPOW distance $(1262 \pm 826 \mathrm{~m})$ and time (1123 $\pm 684 \mathrm{~s})$ compared with an unaided SPOW $(985 \pm 812 \mathrm{~m}$ and $870 \pm 671 \mathrm{~s} ; \quad P<0.05)$ or the draisine-aided SPOW $(586 \pm 508 \mathrm{~m}$ and $468 \pm 361 \mathrm{~s}$; $P<0.05$; Table 2). In addition, the unaided SPOW distance and time were significantly higher compared with a draisine-aided SPOW $(P<0.05$; Table 2). In contrast, the mean SPOW speed was significantly higher while using the draisine compared with the unaided or rollator-aided SPOW $(1.24 \pm 0.23 \mathrm{~m} / \mathrm{s}$ vs $1.07 \pm 0.19 \mathrm{~m} / \mathrm{s}$ and $1.09 \pm 0.14 \mathrm{~m} / \mathrm{s}$, respectively; $P<0.05$; Table 2).

\section{Effects on exercise-induced symptoms}

Symptom scores for dyspnoea and fatigue at start of the SPOW were comparable. Participants reported significantly higher dyspnoea and fatigue scores immediately after the draisine-aided SPOW compared with the unaided or rollator-aided SPOW. Differences in fatigue scores were still significant $2 \mathrm{~min}$ after the SPOW (Table 2). In addition, fatigue scores directly after the rollator-aided SPOW were significantly lower compared with the unaided SPOW (Table 2).

No significant differences were found in heart rate and saturation after the unaided, rollator-aided and draisine-aided SPOW (Table 2).

\section{Effects on SPOW gait variables}

The use of the draisine resulted in significantly fewer strides compared with the unaided and rollator-aided SPOW (301 \pm 234 vs $743 \pm 582$ and $781 \pm 656$, respectively; $P<0.05$, Table 3). Consequently, participants had a significantly greater stride length $(P<0.01$ vs rollator and unaided; Table 3 ) and lower stride frequency $(P<0.05$ vs unaided; Table 3$)$. Moreover, the walk ratio was significantly higher while using the draisine compared with the rollator-aided and unaided SPOW. In addition, step and stride regularity in vertical, anteroposterior and mediolateral direction were significantly lower during the draisineaided SPOW compared with the rollator-aided and unaided SPOW. No significant differences in gait variables were found between unaided and rollator-aided walking.

\section{Patient's preferences}

Twelve participants had never used a rollator before in daily life or during a 6MWT compared with 15 who had never used the draisine (Table 4). Thirteen participants reported to like the rollator. However, only five participants would use it in daily life, of which three had prior experience with a rollator but not using the rollator at the time of enrolment in the study. The proportion of participants who liked the draisine was significantly lower $(P<0.05)$. Although only two of the participants felt embarrassed using the draisine, fewer would like to use the draisine in daily life compared with a rollator (Table 4).

The rollator scored significantly higher in terms of comfort, safety and security $(P<0.05$; Table 4$)$. Lower satisfaction scores for the draisine were caused by problems with the seat, steering problems and/or balance problems. No significant differences were found in satisfaction for dimension, weight, ease in adjusting, ease of use and effectiveness between the walking aids (Table 4), although overall satisfaction for the rollator was significantly higher compared with the draisine $(P<0.05$; Table 4$)$.

\section{DISCUSSION}

The present study is the first to investigate the efficacy of walking aids during a SPOW in individuals with moderate to very severe COPD. Results show that the use of a rollator improves SPOW distance and time compared with an unaided SPOW. In contrast, the use of a draisine had a detrimental effect on distance and time compared with the unaided SPOW.

The efficacy of walking aids during an indoor 6 MWT has been studied frequently, and their use has been associated with significant and clinically relevant improvements in 6MWD. ${ }^{1-3,20,21}$ However, this may not reflect everyday walking, the most frequently reported problematic activity of daily life in COPD. ${ }^{22}$ In addition, individuals with COPD reported to use their walking aids mostly during outdoor activities. ${ }^{8,20}$

This study showed that individuals with COPD gained substantial benefit from a rollator during outdoor walking. While using the rollator, individuals 
Table 2 Outcomes of the self-paced outdoor walks

\begin{tabular}{|c|c|c|c|}
\hline & Unaided $(n=15)$ & Rollator $(n=15)$ & Draisine $(n=15)$ \\
\hline Walk distance (m) & $985.2(812.4)$ & $1261.6(825.8)^{*}$ & $586.2(508.1)^{*,+}$ \\
\hline Walk time (s) & $870.1(671.1)$ & $1123.3(683.5)^{*}$ & $468.3(360.9)^{*, \dagger}$ \\
\hline Walk speed (m/s) & $1.07(0.19)$ & $1.09(0.14)$ & $1.24(0.23)^{*, \dagger}$ \\
\hline Section 1 & $1.12(0.17)$ & $1.11(0.14)$ & $1.28(0.25)^{*, \dagger}$ \\
\hline Section 2 & $1.17(0.12)$ & $1.15(0.14)$ & $1.37(0.27)^{*, \dagger}$ \\
\hline Section 3 & $1.11(0.09)$ & $1.10(0.12)$ & $1.34(0.24)^{*, \dagger}$ \\
\hline Section 4 & $1.00(0.13)$ & $0.92(0.18)$ & $0.95(0.19)$ \\
\hline Borg dyspnoea before (points) & $1.8(1.3)$ & $1.2(0.9)$ & $1.4(1.0)$ \\
\hline Borg dyspnoea after (points) & $5.1(1.7)$ & $4.5(1.6)$ & $5.4(2.1)^{\dagger}$ \\
\hline Borg dyspnoea 2 min after (points) & $3.0(1.6)$ & $2.6(1.2)$ & $3.0(1.6)$ \\
\hline Borg fatigue before (points) & $1.2(1.0)$ & $1.1(0.8)$ & $1.1(0.9)$ \\
\hline Borg fatigue after (points) & $3.9(2.5)$ & $2.9(2.1)^{*}$ & $4.8(2.6)^{*, \dagger}$ \\
\hline Borg fatigue 2 min after (points) & $2.3(1.5)$ & $1.9(1.0)$ & $3.0(1.7)^{\dagger}$ \\
\hline HR before (bpm) & $79.1(10.6)$ & $79.8(9.1)$ & $78.1(8.7)$ \\
\hline HR after (bpm) & $103.7(11.9)$ & $103.5(15.9)$ & $104.1(11.8)$ \\
\hline $\mathrm{SpO}_{2}$ before (\%) & $95.3(2.8)$ & $95.0(2.8)$ & $95.2(2.5)$ \\
\hline $\mathrm{SpO}_{2}$ drop (\%) & $4.1(3.8)$ & $5.5(4.3)$ & $4.7(5.4)$ \\
\hline
\end{tabular}

${ }^{*} P<0.05$ versus unaided; ${ }^{\dagger} P<0.05$ versus rollator.

Results are presented as mean (standard deviation).

bpm, beats per minute; $\mathrm{HR}$, heart rate; $\mathrm{SpO}_{2}$, saturation of peripheral oxygen.

Table 3 Gait variables of the self-paced outdoor walks

\begin{tabular}{lccc}
\hline & Unaided $(n=15)$ & Rollator $(n=15)$ & Draisine $(n=15)$ \\
\hline Strides $(n)$ & $743(582)$ & $781(656)$ & $301(234)^{*,+}$ \\
Stride length $(\mathrm{m})$ & $1.30(0.10)$ & $1.34(0.10)$ & $1.67(0.41)^{*,+}$ \\
Stride frequency (strides/s) & $0.84(0.11)$ & $0.86(0.15)$ & $0.76(0.11)^{*,+}$ \\
Walk ratio (m/steps/s) & $1.57(0.26)$ & $1.59(0.27)$ & $2.29(0.90)^{*,+}$ \\
Step regularity V-trunk & $0.75(0.09)$ & $0.73(0.11)$ & $0.24(0.07)^{*,+}$ \\
Step regularity AP-trunk & $0.63(0.12)$ & $0.69(0.10)$ & $0.18(0.07)^{*,+}$ \\
Step regularity ML-trunk & $0.41(0.23)$ & $0.29(0.30)$ & $0.17(0.10)^{*,+}$ \\
Stride regularity V-trunk & $0.77(0.11)$ & $0.72(0.12)$ & $0.22(0.06)^{*,+}$ \\
Stride regularity AP-trunk & $0.68(0.11)$ & $0.66(0.10)$ & $0.17(0.07)^{*,+}$ \\
Stride regularity ML-trunk & $0.60(0.11)$ & $0.54(0.16)$ & $0.14(0.11)^{*,+}$ \\
\hline
\end{tabular}

${ }^{*} P<0.05$ versus unaided: ${ }^{\dagger} P<0.05$ versus rollator.

Results are presented as mean (standard deviation).

$\mathrm{AP}$, anteroposterior axis; $\mathrm{ML}$, mediolateral axis; $\mathrm{V}$, vertical axis.

with COPD walked on average $276 \mathrm{~m}$ further compared with an unaided SPOW (Table 2), whereas the use of a draisine resulted in a lower SPOW distance and time compared with the unaided SPOW. This is in great contrast with our earlier findings, where we found an increased indoor $6 \mathrm{MWD}$ using a draisine compared with a rollator-aided $6 \mathrm{MWD}{ }^{4}$ This may be due to the fact that the 6MWD was performed indoors on a triangular, flat, enclosed corridor with a hard surface, ${ }^{4}$ while the SPOW was performed on a $250-\mathrm{m}$ course, including straight parts of $78 \mathrm{~m}$. Even though participants were instructed to walk at their own pace, the speed was significantly higher during the use of the draisine compared with the rollator-aided and unaided SPOW. Indeed, mean SPOW speed during the use of a draisine $(1.24 \mathrm{~m} / \mathrm{s})$ was probably too fast for the participants as the mean indoor
6MWD speed was $1.13 \mathrm{~m} / \mathrm{s}$. This hypothesis is supported by the significantly lower distance and duration and higher exercise-induced dyspnoea and fatigue scores during the draisine-aided SPOW.

Several studies have shown that the walk ratio (ratio between stride length and stride frequency) is constant over a large range of walking speeds during normal walking in healthy subjects. ${ }^{23,24}$ Our results show a significantly higher walk ratio in individuals with COPD while using the draisine, indicating an altered walking pattern. The higher walk ratio could be explained by the significantly longer strides. Although participants were instructed to have continuous ground contact, they had the tendency to slightly roll between steps. This alteration in walking pattern could be caused by feelings of uncertainty and imbalance while using the draisine (Table 4). 
Table 4 Data from questionnaire

\begin{tabular}{|c|c|c|}
\hline & Rollator & Draisine \\
\hline \multicolumn{3}{|l|}{ Use of walking aid $(n=15)$} \\
\hline Used before in daily life ${ }^{\dagger}$ & 3 & $0^{*}$ \\
\hline Used before during $6 \mathrm{MWT} ?^{\dagger}$ & 2 & 0 \\
\hline \multicolumn{3}{|l|}{ Feelings of embarrassment $(n=15)$} \\
\hline Did you like the walking aid? ${ }^{\dagger}$ & 13 & $6^{*}$ \\
\hline Were you ashamed using the walking aid? ${ }^{\dagger}$ & 5 & 2 \\
\hline \multirow[t]{2}{*}{ If you were ashamed, why? ${ }^{\dagger}$} & Too young (2) & Afraid for public use (1) \\
\hline & Illness is visible (3) & No reason (1) \\
\hline Would you use it in daily life ${ }^{\dagger}$ & 5 & 3 \\
\hline \multirow[t]{8}{*}{ If not, why not? } & Too heavy (1) & Difficult to move forward (2) \\
\hline & Embarrassed (2) & Much heavier than walking/too heavy (6) \\
\hline & Can easily do without (1) & Steering problems (1) \\
\hline & Too few benefits (1) & Balance problems (1) \\
\hline & Arm swing not possible (1) & Wheels are too small ( 1 ) \\
\hline & Pain in arms (1) & Increase dyspnoea (1) \\
\hline & & Embarrassed (1) \\
\hline & & Preference for rollator $(1)$ \\
\hline \multicolumn{3}{|l|}{ Satisfaction walking aid (D-QUEST) $(n=8)$} \\
\hline Satisfaction dimensions (size, height, length, width) $?^{\ddagger}$ & $3.8(3-4)$ & $3.5(2-5)$ \\
\hline Satisfaction weight? ${ }^{\ddagger}$ & $3.2(1-5)$ & $3.7(3-5)$ \\
\hline Satisfaction ease in adjusting $?^{\ddagger}$ & $3.7(3-4)$ & $3.5(3-4)$ \\
\hline Satisfaction safety and security $?^{\ddagger}$ & $3.8(3-5)$ & $3.0(1-4)^{*}$ \\
\hline Satisfaction ease of use $?^{\ddagger}$ & $3.5(1-5)$ & $3.0(1-4)$ \\
\hline Satisfaction comfort? ${ }^{\ddagger}$ & $4.0(3-5)$ & $3.3(1-5)^{*}$ \\
\hline Satisfaction effectiveness? ${ }^{\ddagger}$ & $3.8(3-5)$ & $3.7(2-5)$ \\
\hline Overall satisfaction $?^{\ddagger}$ & $3.9(2-5)$ & $2.3(1-4)^{*}$ \\
\hline
\end{tabular}

${ }^{*} P<0.05$ versus rollator.

${ }^{\dagger}$ Numbers indicates positive answers.

${ }^{\ddagger}$ Scored using a 5-point satisfaction scale ranging from (1) 'not satisfied at all' to (5) 'very satisfied'. 6MWT, 6-min walk test.

Indeed, an increased walk ratio was shown previously to maintain stability during walking under challenging conditions. ${ }^{25}$

Step and stride variability during the SPOW was higher compared with indoor walking. ${ }^{26}$ Moreover, the use of the draisine resulted in a significantly higher step and stride variability compared with unaided or rollator-aided walking. Earlier it was shown that this increased variability is used as active control strategy to compensate for balance disturbance, ${ }^{27}$ indicating a more imbalanced walking pattern during the draisine-aided SPOW.

A SPOW was used to determine the efficacy of walking aids during outdoor use. This test is not designed to replace field exercise tests, but can be used to acquire more patient-meaningful information. ${ }^{13}$ SPOW time is a direct and immediately understandable measure of a commonly stated goal by individuals with COPD entering pulmonary rehabilitation: to walk for longer. ${ }^{13}$ Furthermore, this test may be more representative of real-life walking, since participants are able to choose their own walking speed. This chosen walking speed is a good indicator for functional status, since a lower walking speed is related to a decline in functional performance and higher mortality in COPD. ${ }^{28,29}$ Moreover, this test can provide meaningful information on walking ability and normal walking pattern in COPD, which may be important, since walking stability in COPD cannot only be attributed to changes in walking speed. ${ }^{26}$ In addition, this information can be helpful for a clinician to determine the choice of a walking aid.

Several methodological limitations need to be addressed. For obvious reasons, it was not possible to blind participants or outcome assessor to the walking aids.

The outdoor practice session of 15 min may be too short for proper familiarizing, especially for the draisine, which had never been used by $95 \%$ of the participants. In fact, some participants reported problems with their balance and felt less safe (Table 4). Since the walking aids were adapted to the size of the participants, these balance problems were not caused by incorrect adjustment, but are likely related to the active support needed to remain stable and alterations in walking pattern. This may improve when participants are able to practise more frequently or for a longer period.

Because of the study design, with no randomization of the unaided SPOW, a carry-over effect might be present. In addition, the study protocol did not include a practice SPOW, and the SPOW was performed on two consecutive days. Since it is possible that a second SPOW is associated with a learning 
effect, the outcomes of this study may be overestimated. However, earlier it was shown that the improvement of a second SPOW was relatively small, and the day-to-day variability is similar to that reported for other frequently used outcomes for pulmonary rehabilitation..$^{13}$ Moreover, additional analyses showed no significant differences in outcomes in the order of walking aid use.

We only included individuals with a baseline $6 \mathrm{MWD} \leq 500 \mathrm{~m}$, since it is expected that they would benefit the most from the use of walking aids. ${ }^{1,12}$ However, since data on the use of a draisine and outdoor use of walking aids are limited, individuals with a $6 \mathrm{MWD}>500 \mathrm{~m}$ might also benefit from the outdoor use of a walking aid. Furthermore, for a higher methodological quality of the study, we only analysed rollator-naïve individuals, and therefore our study was slightly underpowered. However, additional data from five rollator users show similar results, which strengthens our conclusions.

The number of subjects eligible and/or willing to participate is rather low, which may limit the generalization of the results. However, we think it is reasonable to exclude individuals who were not clinically stable, and individuals with neurological, musculoskeletal and/or cardiovascular problems, making it unable to complete a $6 \mathrm{MWT}$ without problems or complaints. In addition, clinical characteristics of eligible individuals who declined to participate were not significantly different in terms of demographics, pulmonary function, body composition and 6MWD from those enrolled in the study. Therefore, it can be assumed that these are not reasons for nonparticipation.

It would be interesting to measure metabolic requirement and dynamic lung hyperinflation. However, data on the validity of a mobile oxycon under different outdoor conditions are limited. Moreover, when using a portable metabolic system, we would not be able to measure individuals with longterm oxygen therapy, who would probably benefit the most from the use of a walking aid. ${ }^{1,2}$

To conclude, a rollator improves SPOW distance and time in individuals with moderate and advanced COPD and a poor functional exercise capacity, whereas the use of a draisine had even a detrimental effect compared with unaided walking. However, the needs and daily use should be considered for selection of a walking aid.

\section{Acknowledgements}

The authors acknowledge the individuals with COPD who volunteered to participate in this study and 'Stichting de Weijerhorst' for funding the study. The sponsor had no role in the design of the study, the collection and analysis of the data, or in the preparation of the manuscript.

\section{REFERENCES}

1 Solway S, Brooks D, Lau L, Goldstein R. The short-term effect of a rollator on functional exercise capacity among individuals with severe COPD. Chest 2002; 122: 56-65.

2 Probst VS, Troosters T, Coosemans I, Spruit MA, Pitta Fde O, Decramer M, Gosselink R. Mechanisms of improvement in exercise capacity using a rollator in patients with COPD. Chest 2004; 126: 1102-7.

3 Gupta R, Goldstein R, Brooks D. The acute effects of a rollator in individuals with COPD. J. Cardiopulm. Rehabil. 2006; 26: 107-11.

4 Vaes AW, Annegarn J, Meijer K, Cuijpers MW, Franssen FM, Wiechert J, Wouters EF, Spruit MA. The effects of a 'new' walking aid on exercise performance in patients with COPD: a randomized crossover trial. Chest 2012; 141: 1224-32.

5 Crisafulli E, Costi S, De Blasio F, Biscione G, Americi F, Penza S, Eutropio E, Pasqua F, Fabbri LM, Clini EM. Effects of a walking aid in COPD patients receiving oxygen therapy. Chest 2007; 131: 1068-74.

6 Hill K, Dolmage TE, Woon LJ, Brooks D, Goldstein RS. Rollator use does not consistently change the metabolic cost of walking in people with chronic obstructive pulmonary disease. Arch. Phys. Med. Rehabil. 2012; 93: 1077-80.

7 Pitta F, Troosters T, Spruit MA, Probst VS, Decramer M, Gosselink R. Characteristics of physical activities in daily life in chronic obstructive pulmonary disease. Am. J. Respir. Crit. Care Med. 2005; 171: 972-7.

8 Hill K, Goldstein R, Gartner EJ, Brooks D. Daily utility and satisfaction with rollators among persons with chronic obstructive pulmonary disease. Arch. Phys. Med. Rehabil. 2008; 89: 1108-13.

9 Spruit MA, Vanderhoven-Augustin I, Janssen PP, Wouters EF. Integration of pulmonary rehabilitation in COPD. Lancet 2008; 371: 12-13.

10 Spruit MA, Pennings HJ, Janssen PP, Does JD, Scroyen S, Akkermans MA, Mostert R, Wouters EF. Extra-pulmonary features in COPD patients entering rehabilitation after stratification for MRC dyspnea grade. Respir. Med. 2007; 101: 2454-63.

11 Hernandes NA, Wouters EF, Meijer K, Annegarn J, Pitta F, Spruit MA. Reproducibility of 6 -minute walking test in patients with COPD. Eur. Respir. J. 2011; 38: 261-7.

12 Spruit MA, Mercken EM, Wouters EFM, Schols AMWJ. Role of exercise testing in defining response to interventions in COPD patients. Eur. Respir. Mon. 2007; 40: 208-20.

13 Evans RA, Hill K, Dolmage TE, Blouin M, O'Hoski S, Brooks D, Goldstein RS. Properties of self-paced walking in chronic respiratory disease: a patient goal-oriented assessment. Chest 2011; 140: $737-43$.

14 Spruit MA, Singh SJ, Garvey C, Zuwallack R, Nici L, Rochester C, Hill K, Holland AE, Lareau SC, Man WD et al. An official American Thoracic Society/European Respiratory Society statement: key concepts and advances in pulmonary rehabilitation. Am. J. Respir. Crit. Care Med. 2013; 188: e13-64.

15 Demers L, Weiss-Lambrou R, Ska B. The Quebec User Evaluation of Satisfaction with Assistive Technology (QUEST 2.0): an overview and recent progress. Technol. Disabil. 2002; 14: 101-5.

16 Wessels RD, De Witte LP. Reliability and validity of the Dutch version of QUEST 2.0 with users of various types of assistive devices. Disabil. Rehabil. 2003; 25: 267-72.

17 Borg GA. Psychophysical bases of perceived exertion. Med. Sci. Sports Exerc. 1982; 14: 377-81.

18 Perneger TV. What's wrong with Bonferroni adjustments. BMJ 1998; 316: 1236-8.

19 Lacasse Y, Goldstein R, Lasserson TJ, Martin S. Pulmonary rehabilitation for chronic obstructive pulmonary disease. Cochrane Database Syst. Rev. 2006; (4): CD003793.

20 Gupta RB, Brooks D, Lacasse Y, Goldstein RS. Effect of rollator use on health-related quality of life in individuals with COPD. Chest 2006; 130: 1089-95.

21 Holland AE, Hill CJ, Rasekaba T, Lee A, Naughton MT, McDonald CF. Updating the minimal important difference for six-minute walk distance in patients with chronic obstructive pulmonary disease. Arch. Phys. Med. Rehabil. 2010; 91: 221-5.

22 Annegarn J, Meijer K, Passos VL, Stute K, Wiechert J, Savelberg $\mathrm{HH}$, Schols AM, Wouters EF, Spruit MA. Problematic activities of daily life are weakly associated with clinical characteristics in COPD. J. Am. Med. Dir. Assoc. 2012; 13: 284-90. 
23 Nagasaki H, Itoh H, Hashizume K, Furuna T, Maruyama H, Kinugasa T. Walking patterns and finger rhythm of older adults. Percept. Mot. Skills 1996; 82: 435-47.

24 Terrier P, Schutz Y. Variability of gait patterns during unconstrained walking assessed by satellite positioning (GPS). Eur. J. Appl. Physiol. 2003; 90: 554-61.

25 Menz HB, Lord SR, Fitzpatrick RC. Acceleration patterns of the head and pelvis when walking on level and irregular surfaces. Gait Posture 2003; 18: 35-46.

26 Annegarn J, Spruit MA, Savelberg HH, Willems PJ, van de Bool C, Schols AM, Wouters EF, Meijer K. Differences in walking pattern during 6-min walk test between patients with COPD and healthy subjects. PLoS ONE 2012; 7: e37329.

27 Moe-Nilssen R, Helbostad JL. Interstride trunk acceleration variability but not step width variability can differentiate between fit and frail older adults. Gait Posture 2005; 21: 164-70.
28 Spruit MA, Polkey MI, Celli B, Edwards LD, Watkins ML, Pinto-Plata V, Vestbo J, Calverley PM, Tal-Singer R, Agusti A et al. Predicting outcomes from 6-minute walk distance in chronic obstructive pulmonary disease. J. Am. Med. Dir. Assoc. 2012; 13: 291-7.

29 Cooper R, Kuh D, Hardy R. Objectively measured physical capability levels and mortality: systematic review and meta-analysis. BMJ 2010; 341: c4467.

\section{Supplementary Information}

Additional Supplementary Information can be accessed via the online version of this article at the publisher's website:

\section{Appendix S1 Methods.}

Table S1 Weather conditions during SPOW. 